\title{
OPINIONS OF GOVERNMENTAL EXTENSION LEADERS IN SOME EGYPTIAN GOVERNORATES CONCERNING THE RE-ENGINEERING OF ADMINISTRATIVE PROCESSES IN THE AGRICULTURAL EXTENSION ORGANIZATION
}

(Received: 31.12.2019)

\author{
By \\ Hanan K. Abdelhalim and Dina H. Emam* \\ Agricultural Extension \& Rural Development, Research Institute, \\ Agricultural Research Center, Giza, Egypt. \\ *Department of Rural Sociology and Agricultural Extension, Faculty of Agriculture, \\ Cairo University, Giza, Egypt.
}

\begin{abstract}
The present study investigated the opinions of the extension work leaders concerning the implementation of the reengineering technique on agricultural extension organization, the success factors of the application and obstacles of this technique in the agricultural extension organization. The study was conducted in El Dakahlya, El-Qalyubia, El-Fayum, and Bnei Suef Governorates. The study covered the population of 140 respondents. The data were collected by personal interviews with the respondents, using a questionnaire designed and pre-tested to achieve the study objectives. Frequencies and percentages were used for data presentation and analysis.

The main results of the study could be summarized as follows:

1 - Considerable proportions ( $80 \%$ ) of the respondents mentioned that the application of reengineering technique encourages the use of Information Technology. This technique facilitates communication between farmers and agricultural extension, and the extension organization needs to apply it, as reported by $78 \%$ and $72 \%$, respectively

2 - The majority (85\%) of the respondents reported that the application of reengineering technique facilitates the communication between farmers and change agent and helps to provide good extension services to achieve the satisfaction of farmers, as reported by $80 \%$. Applying this technique helps to provide timely extension services and speed up offering solutions to farmers' problems, as mentioned by $79 \%$ for both of them.

3 - Applying this technique facilitates handling farmers' problems and reduces the duplication of work of the extension organization's personnel, and 50\% said that applying engineering increases work productivity, as reported by $70 \%, 67 \%$ and $50 \%$ of the respondent respectively.

4 - The most important success factors of reengineering technique are: Providing qualified and welltrained personnel, securing information exchange technology systems, providing modern equipment, providing the necessary physical resources, and gradual application of this technique, as reported by $81 \%, 74 \%, 70 \%, 69 \%$, and $66 \%$, respectively

5 - The main obstacles for applying the reengineering technique are: The lack of qualified personnel (75\%), insufficient financial resources needed for performing the needed procedures $(73 \%)$ and lack of satisfactory salaries and financial incentives $(70 \%)$.
\end{abstract}

Key words: re-engineering, re-designing, agricultural extension organization, administrative processes. 


\title{
آراء قادة العمل الإرشادي الحكومي ببعض محافظات مصر في إعادة هندسة العمليات الإدارية داخل المنظمة الإرشادية الزراعية في في اعلية
}

\author{
حنان كمال عبد الحليم ـ*دينا حسن إمام
}

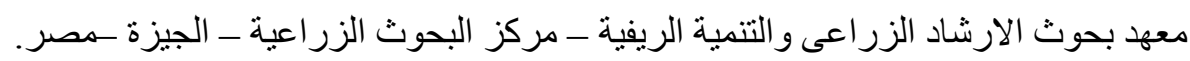

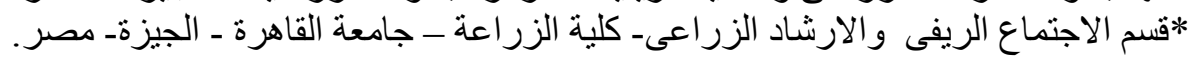

\begin{abstract}
ملخص الإرمادي

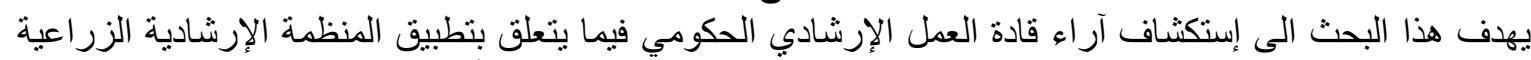

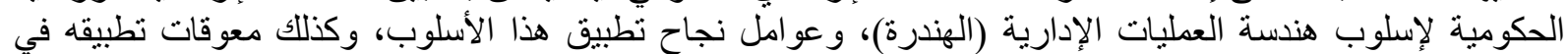

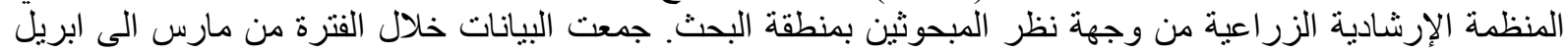

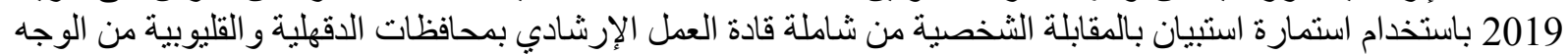

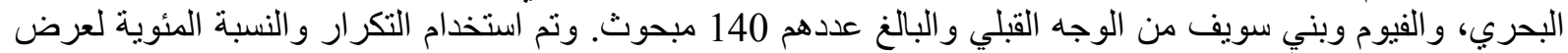

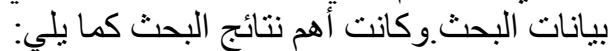

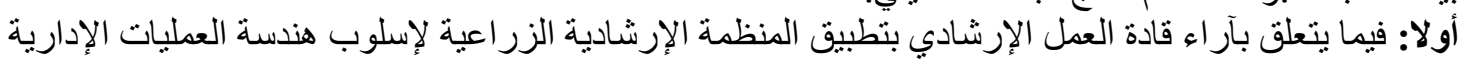

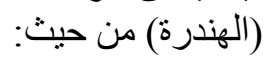

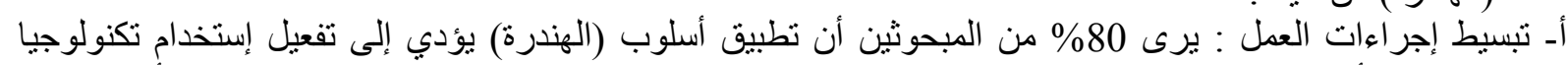

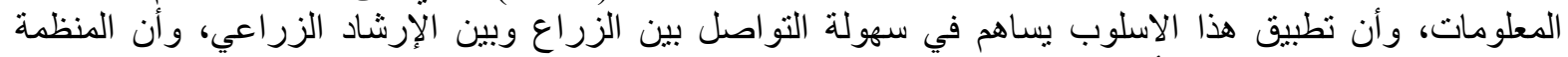

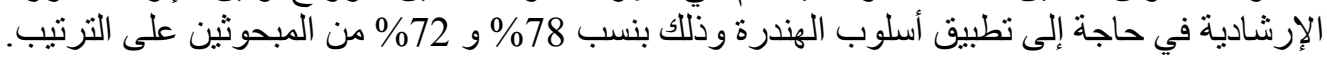

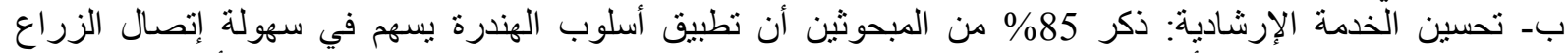

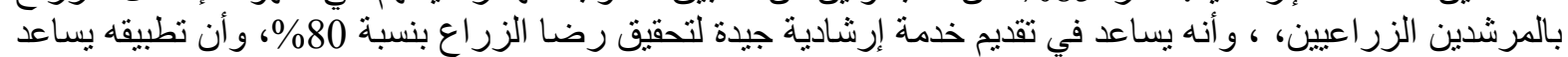

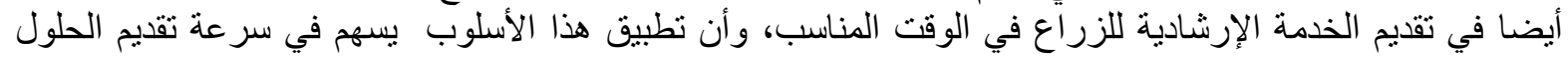

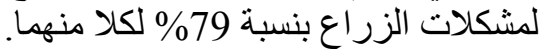

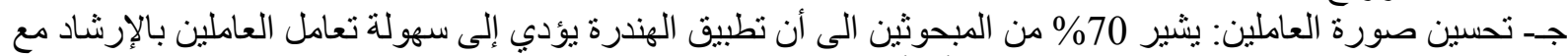

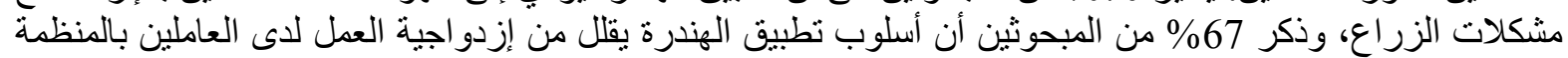

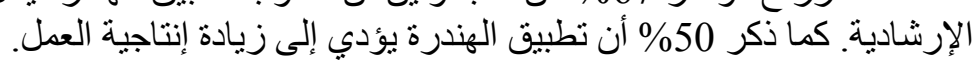

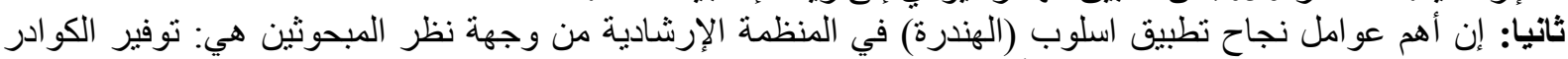

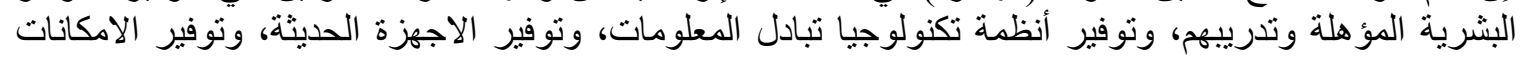

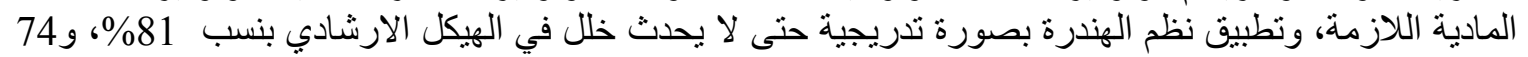

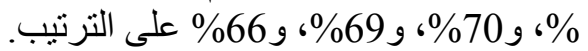

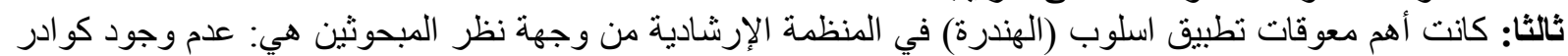

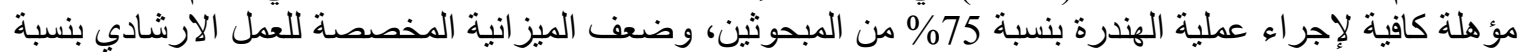
73\%، و وارتفاع التكاليف و الذي يؤدي اللى إعاقة عملية الهندرة، وضعف المرتبات والحو افز المادية وذللك بنسبة الإنة

\% \% 70 كلا منهما.

أولا: القدرة على التكيف مع منطلبات التغيير ات التي تحدث بالبيئة.

ثثاتيا: الإحساس بالذات ألات أو الهوية والى أي مدى تعتبر

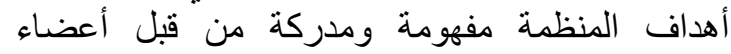

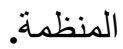

ثالثا: القدرة على اختبار الواقع والتفسير الصحيح للسمات

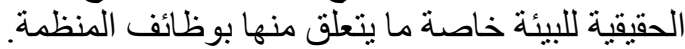

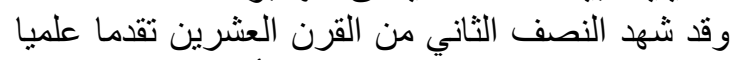

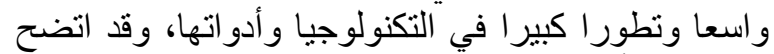

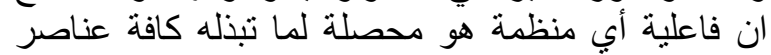
المنظمة في التطوير والتحديث المئمة المستمر لتقديم خدمة

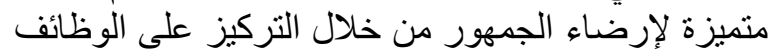

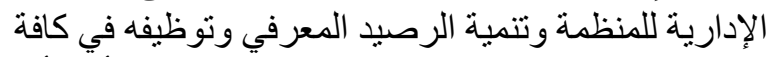
عملياتها .وتعتبر الوظائف الإدارية مهمة بالنسبة لادئاء أي

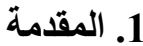

تسعى الحكومة المصرية في الوقت الرمائ الهادن إلى تنفيذ

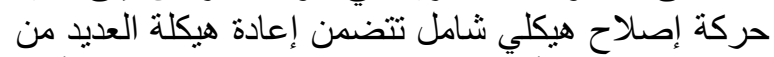

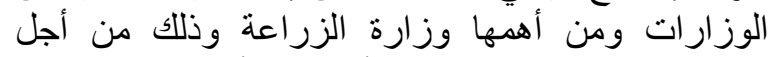
تمكينها من آداء المهام بكفاءة وأيضا من أزباء أجل تحقيق التنمية

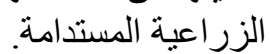

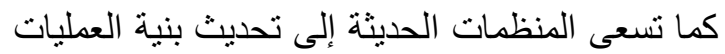

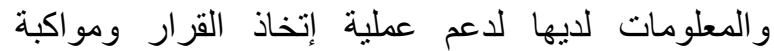
التغيرات التي تحدث في بيئتها المحيطة وزيلية التيادة قدرتها

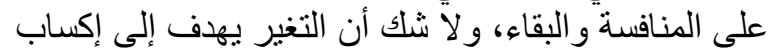

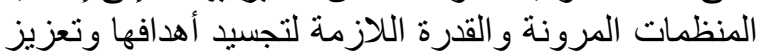

تقافتها بما يخدم نظرنها المستقبلية وخطتها المنا الإستر اتيجية.

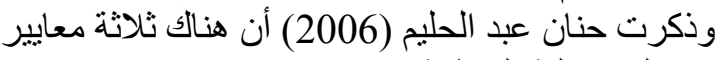

للحكم على فاعلية المنظمة وهي: 
العمليات داخل المؤسسة من أجل تطوير الإنتاجية كماً

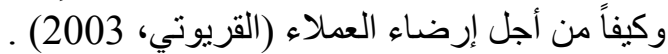

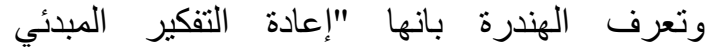

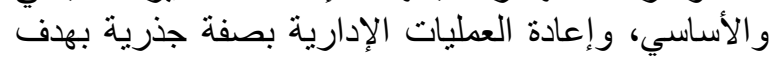
تحقيق تحسينات جوهرية فائقة وليس هامثية الأراية تدريجية في معايير الأداء الحاسمة، مثل التكلفة و الجودة والنة والخدمة

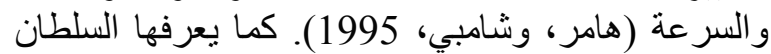

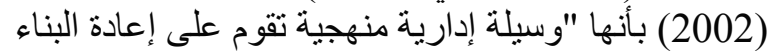

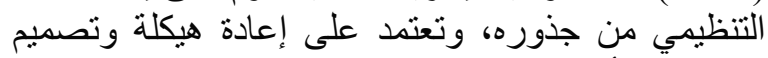

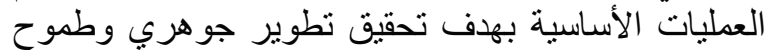

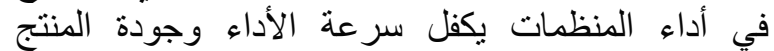
وتخفيض التكلفة". و عرفها "حريم" (2003) بأنها "إعادة النية

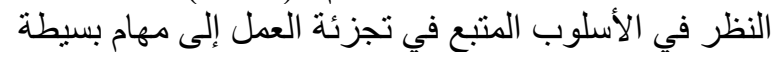
إلى إعادة إدماج المهام الرئيسية في عمليزية العمل الميات متماسكة بحيث تبدأ المنظمة العمل من الصفر في في إعلئ فيلة تصميم

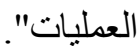

كما ذكر كلا من (Raymond and Bergeon,1998) أن إعادة هندسة العمليات الإدارية (الهندرة) عبارة عن:

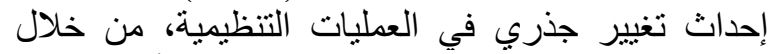
إستخدام تكنولوجيا المعلومات الإستخدام الأمثل وذلكي لتحقيق تحسينات جوهرية في الجودة و الآداء و الإنتاج . كما عرفها (Neill and Sohal 1999) بأنها إعادة الهيكلة المتزامنة لكلا مـن عمليـات المنظمة والهيكل

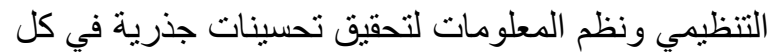
من الوقت و التكلفة وكل ما يتعلق بالسلع و الخدمات المقاتئة

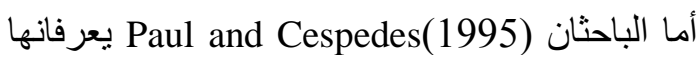
بانها عبارة عن منهج لتحقيق التطوير التوبير الجذري في آداء

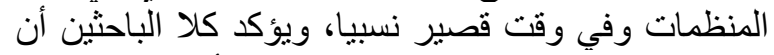

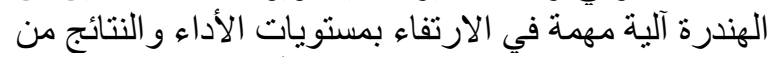

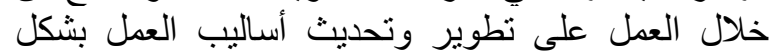
بساعد على إحداث طفرة في الأداء خلال فترة زمنية العبل قصبرة .

ويرى Hammer and Champy (1993) أن الهندرة

تعني البدء من جديد أبي من نقطة الصفر، وليس إصلاح الصناح

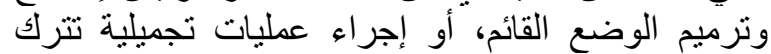

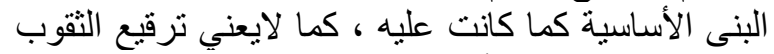

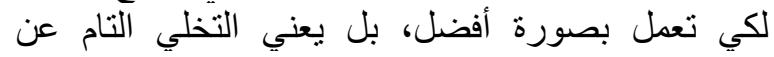

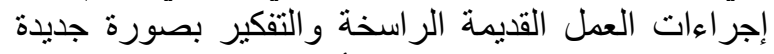
ومختلفة في تصنيع المنتجات، أو تقديم الخدمات لتحقيق التحيق

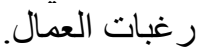

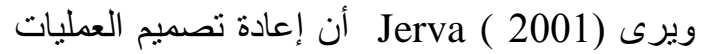

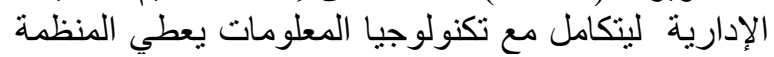

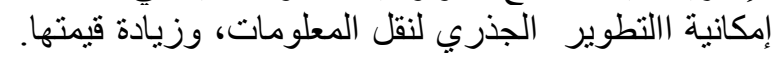
كما تؤدي الى خفض التكلفة وزيادة التمايز في المنتجات التهات، التهات

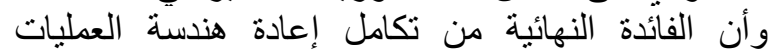

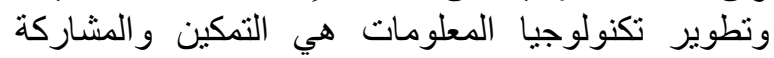

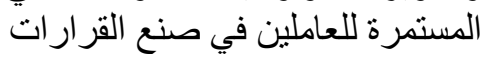

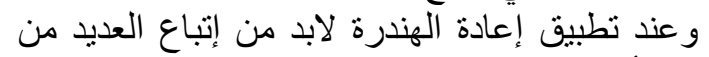
المبادى أهمها البدء بالعمليات ذات الثنات القيمة المضافة ثن
منظمة، حيث تمثل الإدارة أهم الوسائل التي تستثمرها المنظمات لتحقيق التقام، وذلك بسبب الإدارة التغير التئ الاجتماعية و الاقتصادية و التقنية المحيطة بالمنظمة.

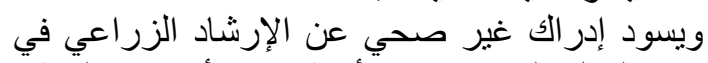

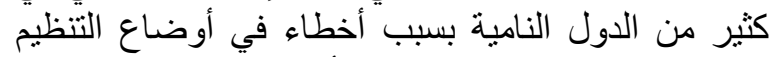

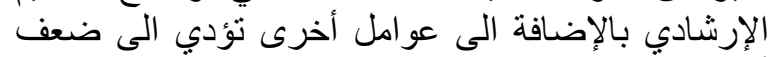

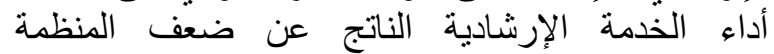

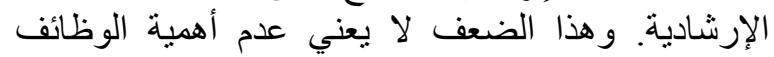

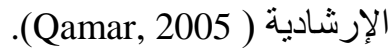
ويواجه الإرشاد الزراعي في مصر العديد من أوجها

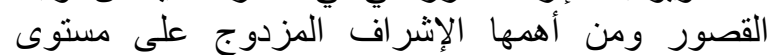

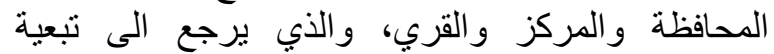
العاملين الإرشاديين الزراعيين فنبا ألى الإدارة المركزية المية لئية

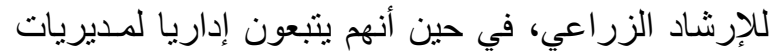

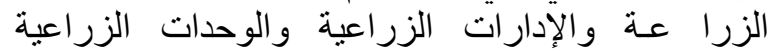

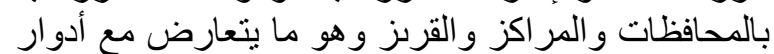

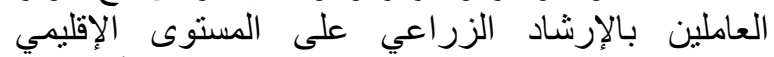

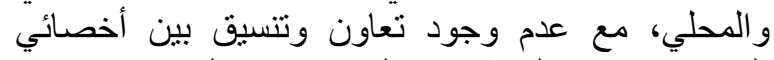

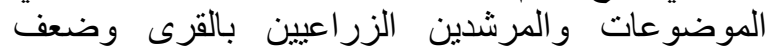
الروابط بين الزراع و الباحثين و المرشدين على المين المستوى

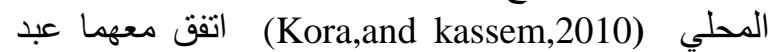
العال (2006) كما أضاف أنه لا يمكن النظر إلى ماسبق أنداف

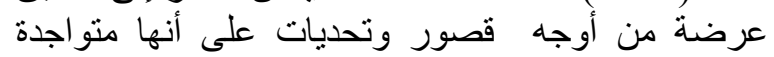

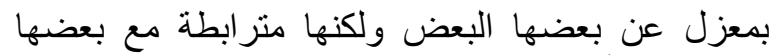

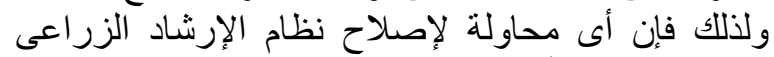

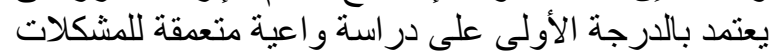

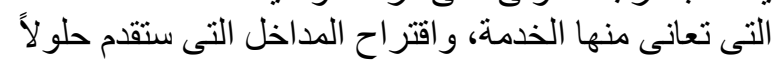

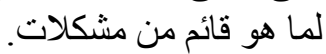

وتنشأ حاجة المنظمات للتغيير من وجنات التهود فجوة بين

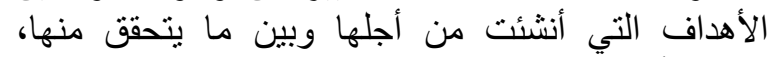

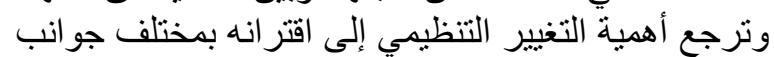

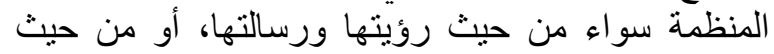
سلوك الأفراد العاملين و إتجاهاتهم و إجراءات اتهات المنظمة العنة

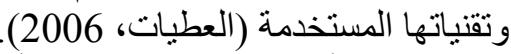

ونظرا لأن معظم منظمات الأعمال في العضات العصر

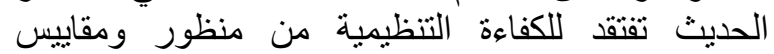

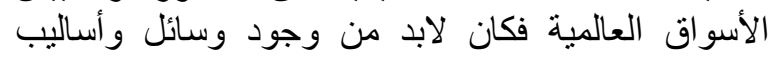

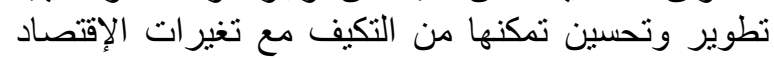

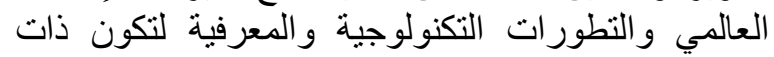
كفاءة وفعالية. لذلك فإعادة هندسة العمليات تعد بمثابة ثورة لتونة

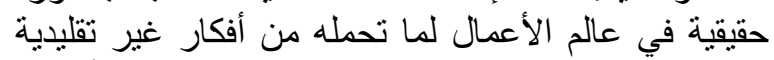
ودعوة لإعادة التفكير و النظر بشكل جذري في كالفة التئ أنشطة وإجراءات و إستر اتيجيات العمل التي أسست علئ عليها العديد

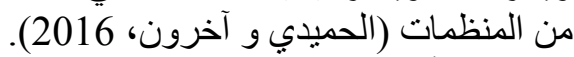
ويعد أسلوب إعادة هندسة العمليات الإدارية (الهندرة)

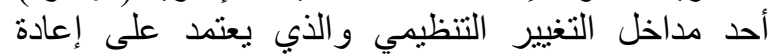

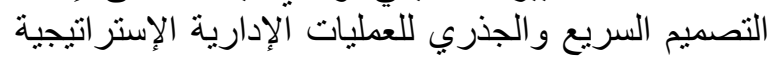

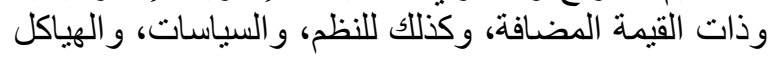

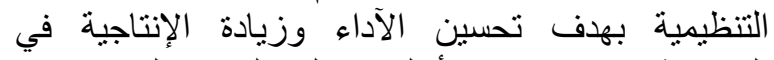
المؤسسة. ويركز هذا الأسلوب على التغيير الجذري في في فئي 
4 - تهتم بالنتائج وتركز على حاجة العميل الداخلي و الخارجي.

5 - تقوم على هيكلة العمل على أساس العملية ككل، على القى

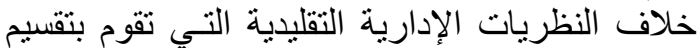
العمل إلى مجمو عة يقوم بها مجمو عة من الإدية الموظفين. 6 - تتميز بأنها تبدأ من النشكيك في مشروعية التهائ العملية

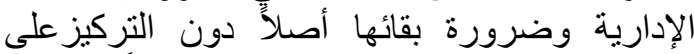

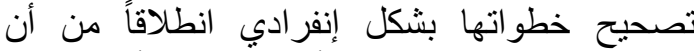

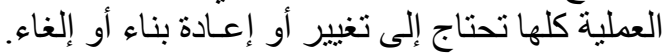
7 - تركز على إعادة تصميم نظم العمل الأساسية، ولاء لألاء

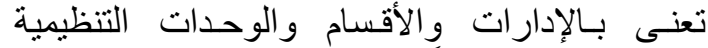
المتعارف عليها تقليداً.

8 - تقوم على نقد أنشطة الرقابة والمر اجعة بصورتها التقليدي الضخمة، انطلاقاً من إيمانها بـأتكلفتها

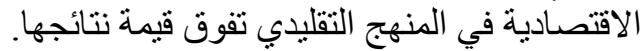

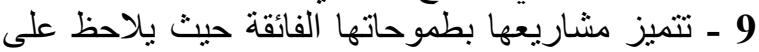

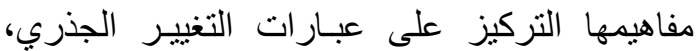
(تحسينات جوهرية) (بناء أساسي) (إعادة تصميم كلي).

10 - الاعتماد بشكل رئيس على تقنية المعلومات أساساً ل لمشاريعها.

الاسرات السابقة

1. دراسة مرام الأغا (2006)، بعنوان "دراسة الطانة تطبيقية

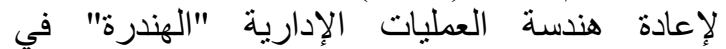
المصارف في قطاع غزة"، و واستهدفت الإنة الدراسة التعرف علي العلاقة بين إعادة هندسة العادة العمليات الإدارية (الهندرة) في المصارف في قطاع فاع غزة وبين

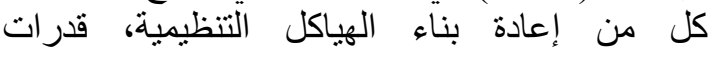

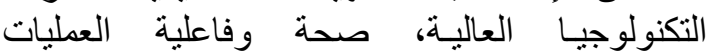

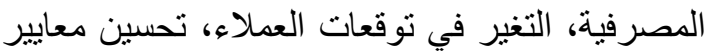

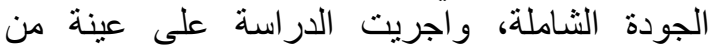

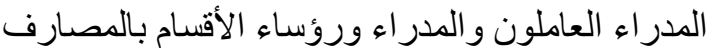

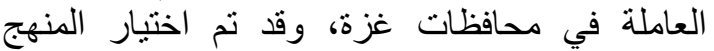
الوصفي التحليلي والاعتماد على استمارة الاستبيان

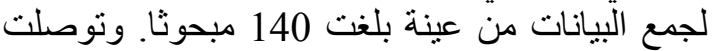

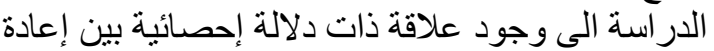

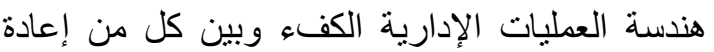
بناء الهياكل التنظيمية، وقدرات الآدية تكنولوجيا عالية ولية، و

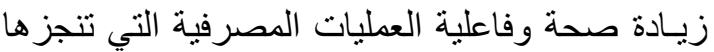
هذه المصارف، و التغير ات في توقعات العميل، وكذللك تحسين معايير الجودة الثناملة .

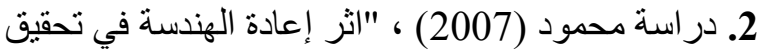

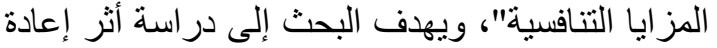

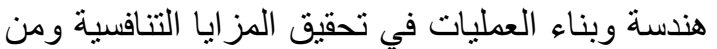

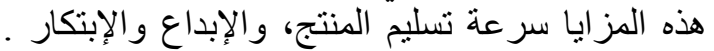
ونم اختيار شركة واسط للصناعات الهنات النسيجية باعتبار ها الإنا احدى منظمات القطاع الصناعي العر اقي التي التئي تحتاج الى التميز في السوق، وجمعت البيانات باستخدام استمارة استبيان، ونم تحديد عينة البحث من الذين
تحديد العمليات المساعدة، وإدماج تكنولوجيا المعلومات

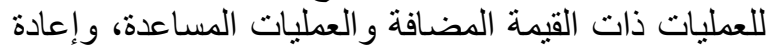

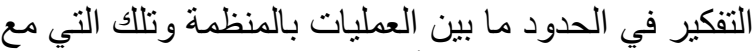

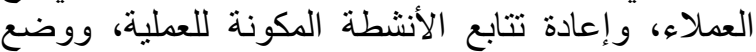
المقارنة المرجعية للعملية، وتحدى مبادئ التنظيم التقليدية التية (الرفاعي، 2006).

ويذكر هامر وشامبي (1995) المحاور او العناصر الرئيسية لإعادة هندسة العمليات الإدارية و هي كالئي الآتي: 1.إعادة التفكير بشكل أساسي (Fundamental Rethinking): يذكر (خبير،2008) إن الهندرة تطرح أسئلة أساسية لا تقتصر فقط على الطرق والأساليب الإدارية الطية الطية المستخدمة، بل تلجاوز ها إلى اللى الأعمال نفسها و الفرضيات التي تقوم عليها تلك الأعمال. 2. إعادة تصميم جذري (Radical Redesig) : حيث الأرمال

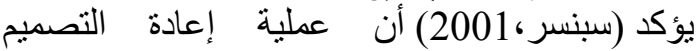
الجذرية تعنى التغير من الجذور وليس مجرد تغير إعيرات

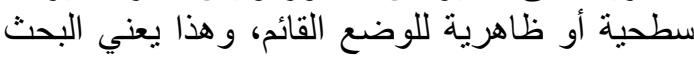

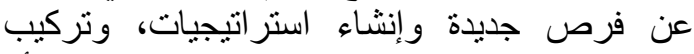

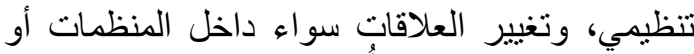

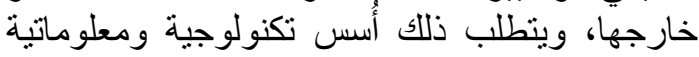
جديدة.

3. نتائج جو هرية (Dramatic Results): إعادة الهندسة لا

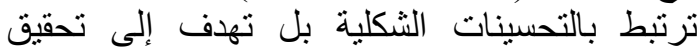

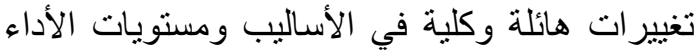

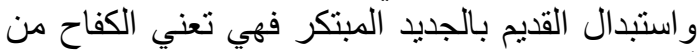
أجل تحقيق مستويات فائقة من التحسين. وذلكي فئل يعني

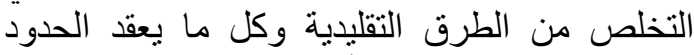

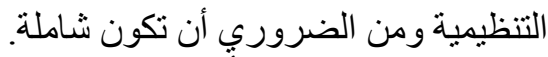

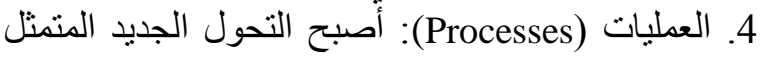

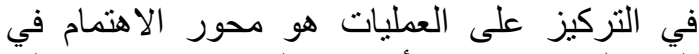

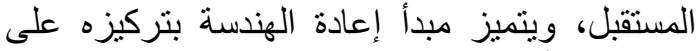

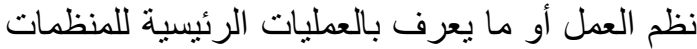

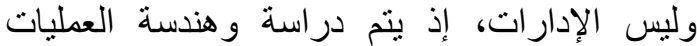
بكاملها ابتداءً من استلام طلب العميل إلى أن ينت إندارة إنجاز

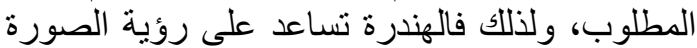

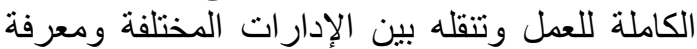

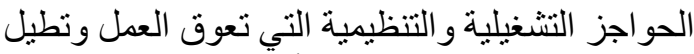
من الزمن اللازم لتقديم المنتج أو النجاز الخدمة والعمل ونطيل

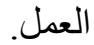

\section{خصائص إعادة هندسة العمليات} استخلص السلطان عدة خصائص لإعادة هندة الإنة العمليات الإداريـة منها (السلطان، 2002):

1 - إعادة هندسة العمليات الإدارية تبدأ من نقطة الصفر الإن الصاء

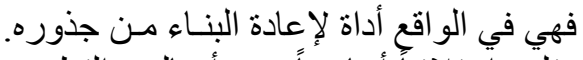

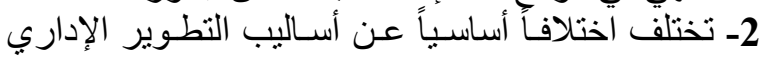

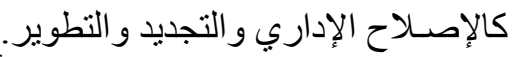

3- تركز على العمليات الإدارية لا لإلى على الأنشطة كما هو الإلئ الحال بالنسبة لأساليب التنظيم الإدارية التقليدية. 
النشاملة، لكن بدرجة متوسطة.

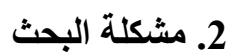

تبرز أهمية التغيير التنظيمي كأحد أهم أنواع التغيير

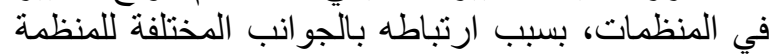
سواء من حيث رؤيتها ورسالتها، أو من حيث الت الث عملياتها ومهامها و هياكلها التنظيمية، أو من حيث التهات سلوك الك الأفراد العاملين و واتجاهاتهم و والإجراءات التطية المنظمة و وتقنتياتها الحديثة، وقد أدى التطور السريع وظهور التكنولواتوجيا

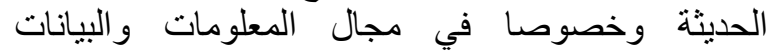

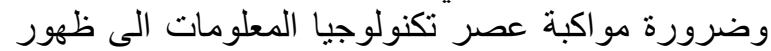

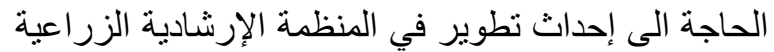

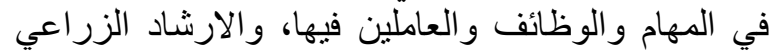
كمنظمة رسمية لها أهيتها في نقل المعلومات الهيات الى جمهور

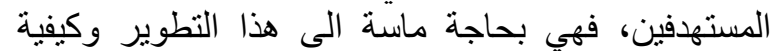

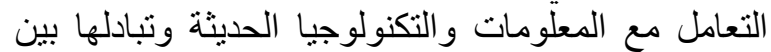
العاملين بالتنظيم الإرشادي وتشجيع التشيع الإبتكار والتجديد

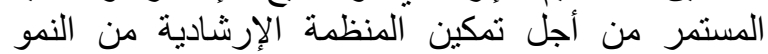

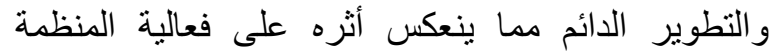

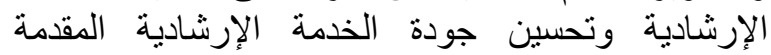

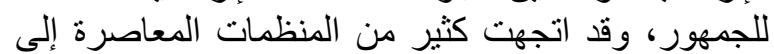

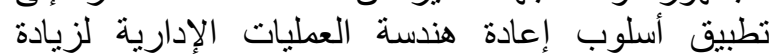

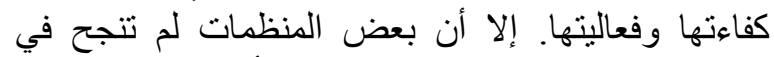

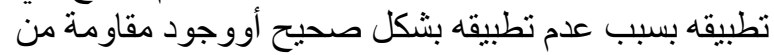

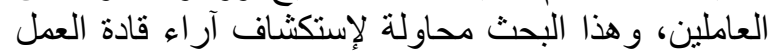
الإرشادي في مدى إمكانية تطبيقه في المنظمة الإرشادية و أسباب نجاح أو فئل التطبيق. ويعتبر هذا البحث استكمالا للبحوث التبن التي تمت في مجال

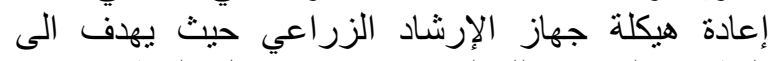

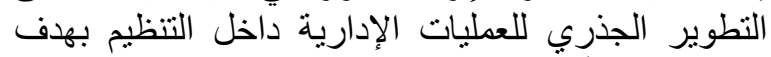

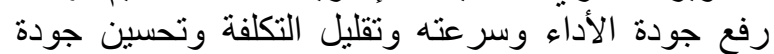
الخدمة المقدمة للجمهور.

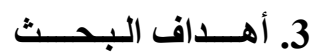

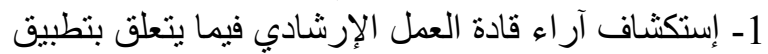

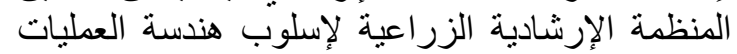

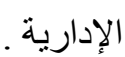

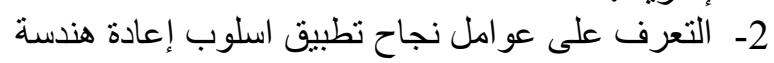

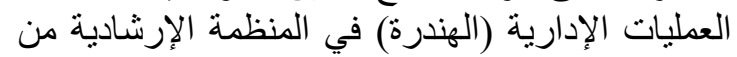
وجهة نظر المبحوثين. 3- التعرف على العى معوقات تطبيق اسلوب إلعاد إعادة هندسة

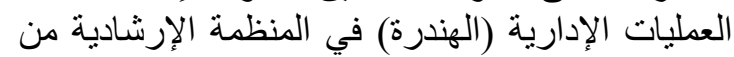

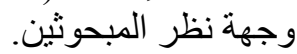

\section{4. - الطريقة البحثية}

التعريفات الإجرائية

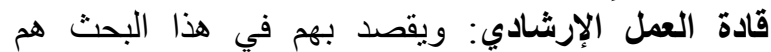

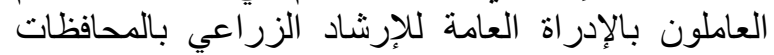

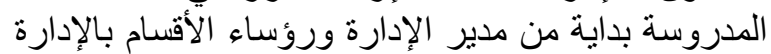
والأخصائيين ثم رؤساء أقسام الإرشاد على على مستوى بالإدارة

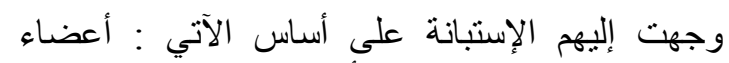

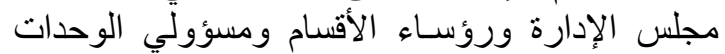

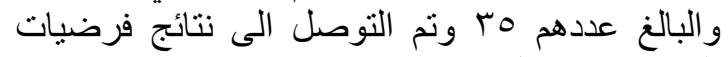

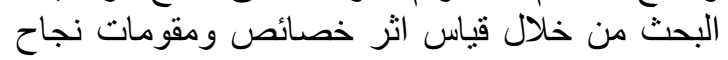

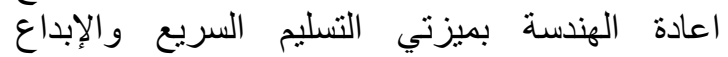

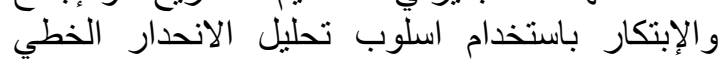

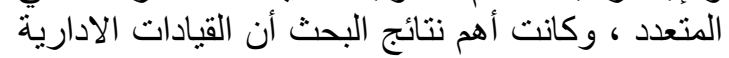

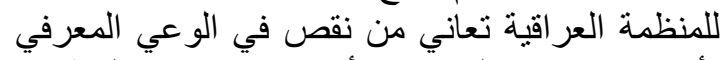

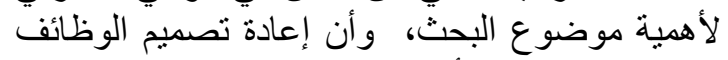

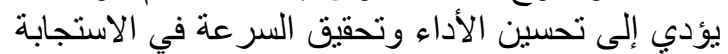

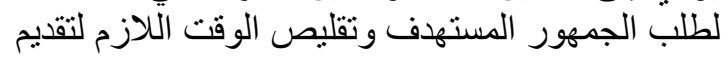

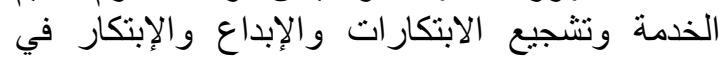

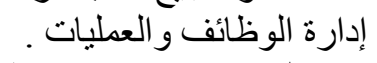

3. دراسة الخواجا (2008) "تطوير نموذج لإعادة الإنة هندسة

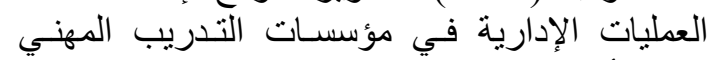

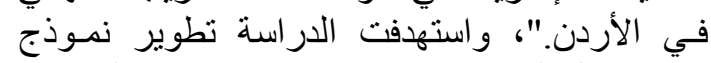

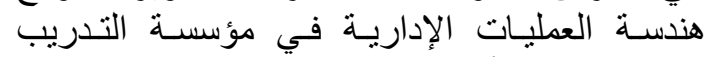

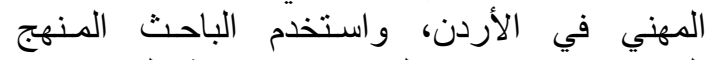

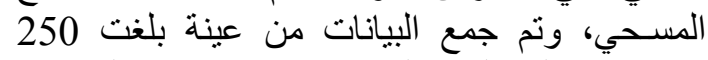

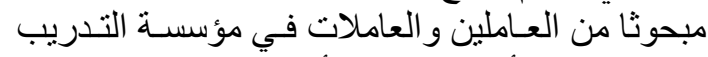

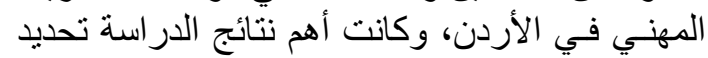

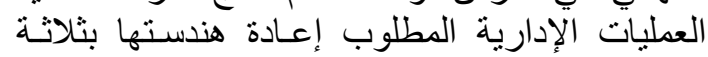

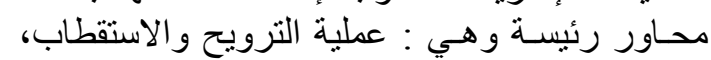

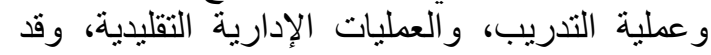

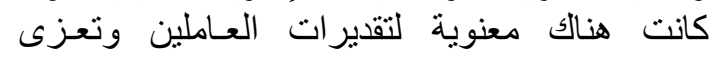

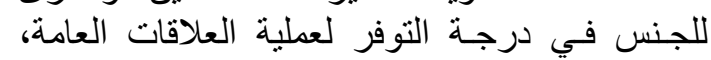

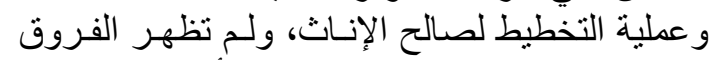
بين الجنسين من حيث دربة درجة الأهمية للعمليات

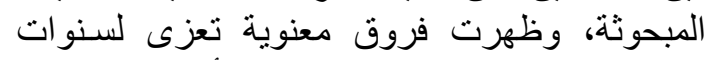

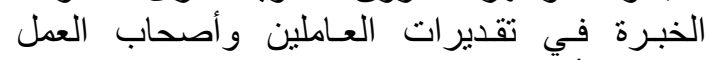

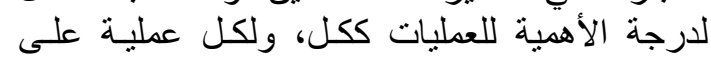
حده، وذلك لصالح العاملين الذين خبرتئ ونهم خمس على

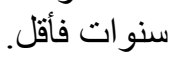

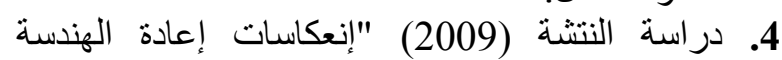

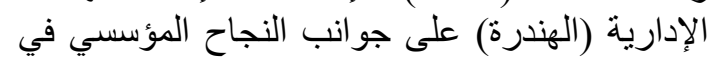

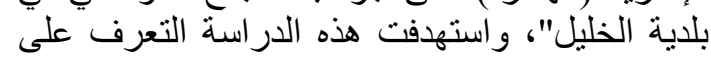

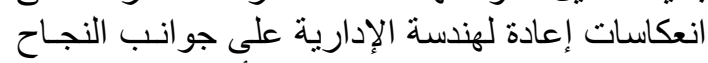

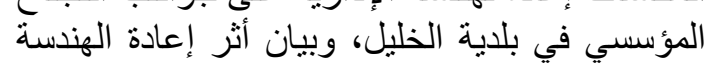

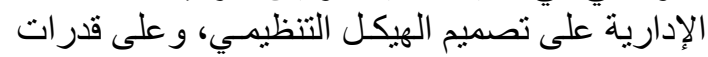

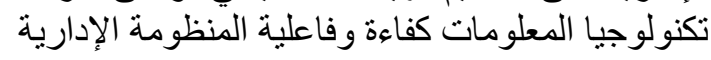

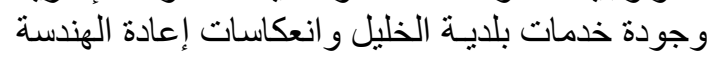

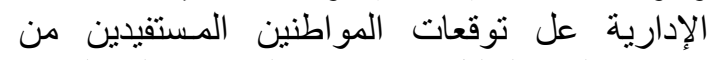

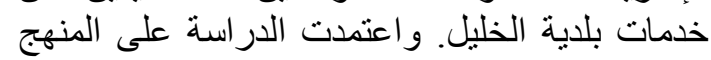

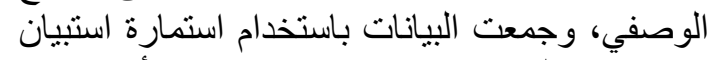

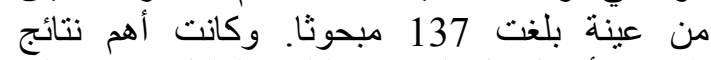

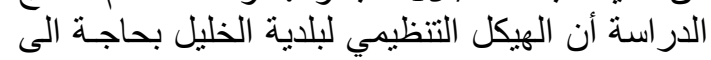

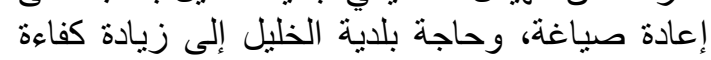

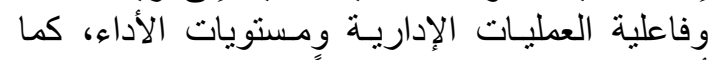

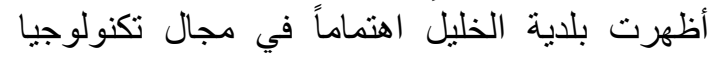

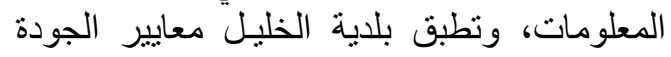


المعلومات عند تطبيق أسلوب الهندرة، وعدم فاعلية

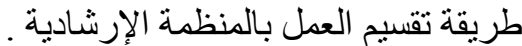

2- البعد الثاني: تحسين الخدمة الإرشادية المقدمة

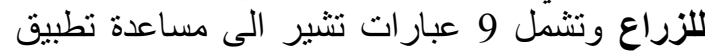

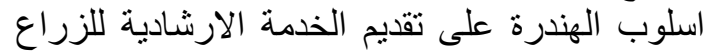

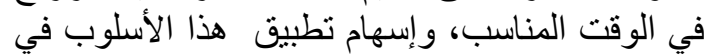

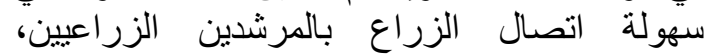

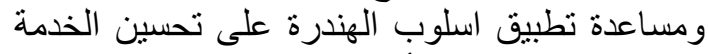

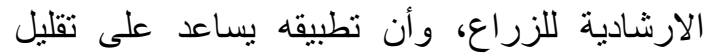

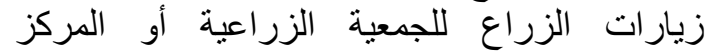
الإرشادي، كما يساهم تطبيقه في سرعة تلقدية الزيم الحلول

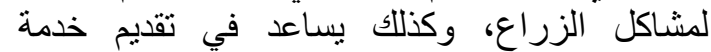

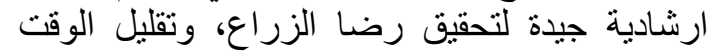

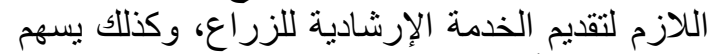

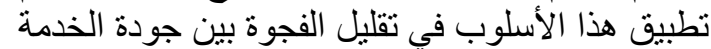
المتوقعة والجودة الفطلية للخدمة الارشادية المقدمة بلثة الخدة

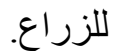

3- البعد الثالث: تحسين صورة العاملين ويشمل 15

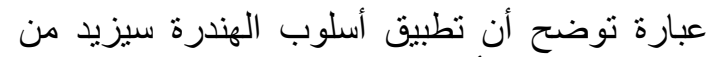

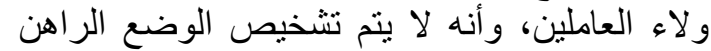

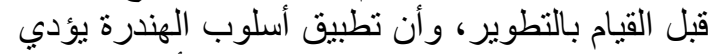
الى انخفاض في معنويات العاملين، وأنه لا لا حاجة النة

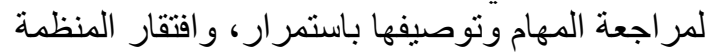

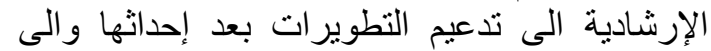

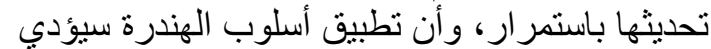

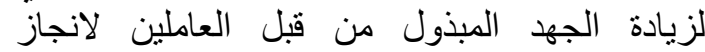

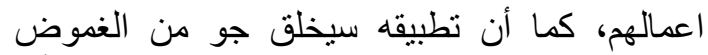
و عدم الوضوح بين العاملين بالمنظمة الإرشادية، وانية وأنه

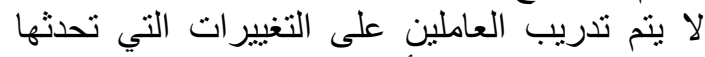

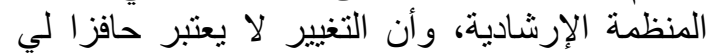

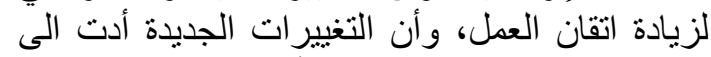

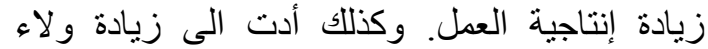

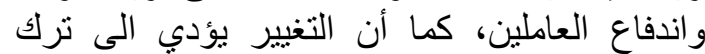

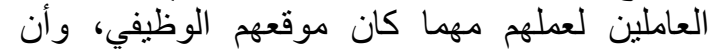

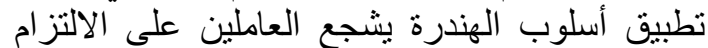

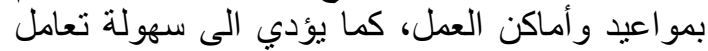

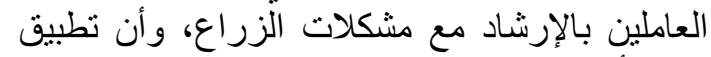

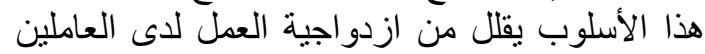

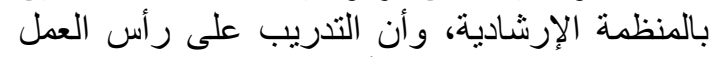

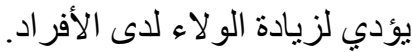

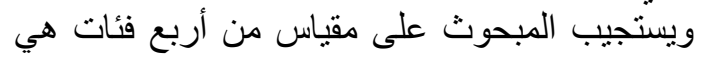

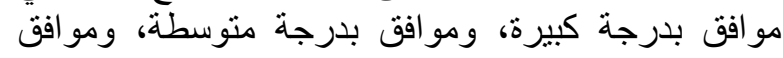

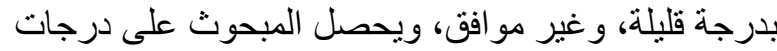

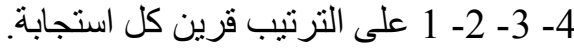

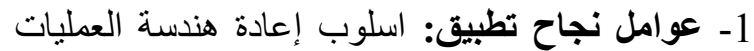
الإدارية (الهندرة) في المنظمة الإرشادية وتشمل 12 عبارة يستجيب عليها المبحوث في حالة والة وجودها. 2- معوقات تطبيق: اسلوب إعادة هندسة العبدة العمليات

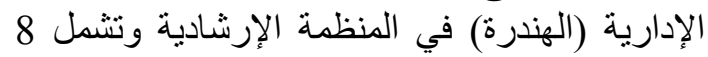
عبار ات يستجيب عليها المبحوث في حالة وجودها.

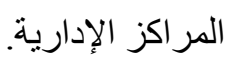
إعادة هندسة العمليات الإدارية (الهندرة): ويقصد بها في

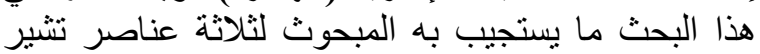

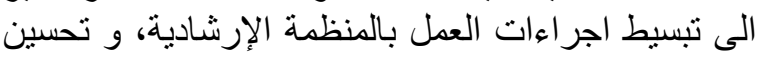

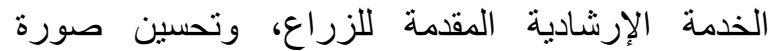

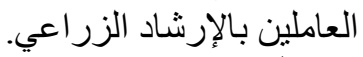
تبسيط إجراءات العمل: ويقصد بهاء بها تقليل أخطاء العمل من العناء

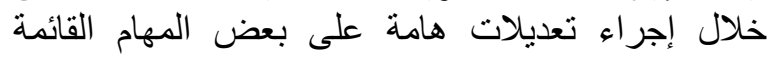

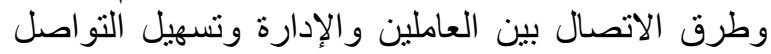

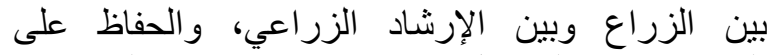

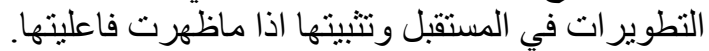

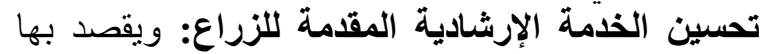

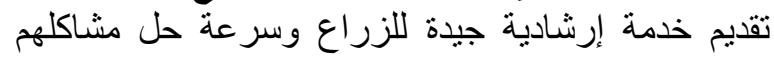

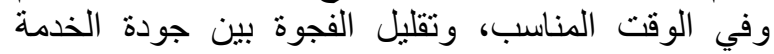

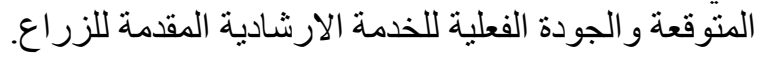
تحسين صورة العاملين: ويقصد بها زيادة ولاء الاء العاملين

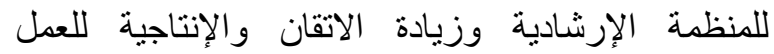

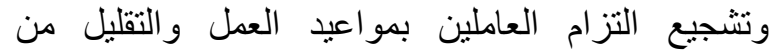
ازدواجية العمل ورفع كفاءة العاملين بالمنظمة الإرشادية التهادية

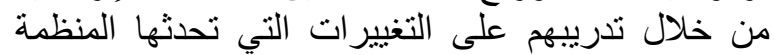

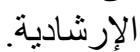

منطقة وشاملة البحث

واجرى هذا البحث بأربع محافظات هي الدقهلية

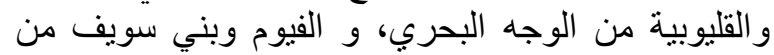

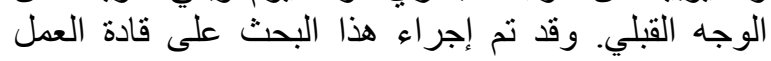

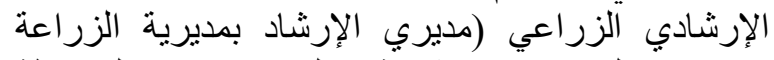

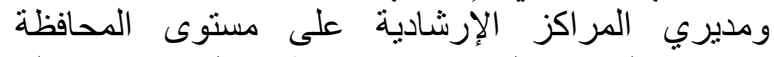

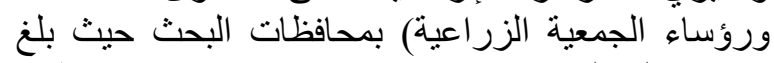

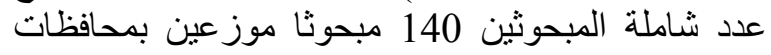

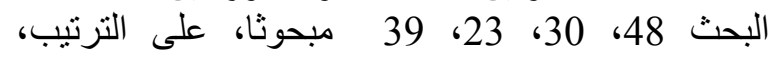

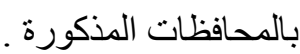
استمارة الاستبيان

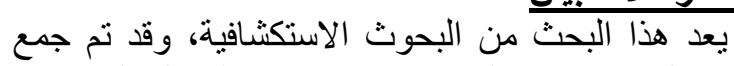
بيانات البحث من خلال إستمارة إستبيان بالمقابلة الثخصية

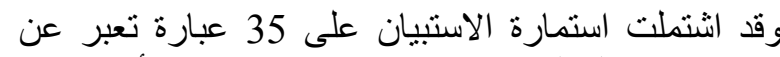

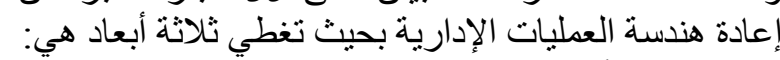

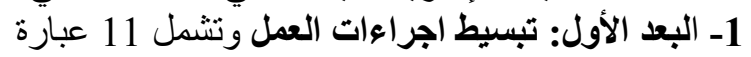

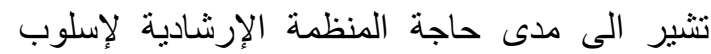

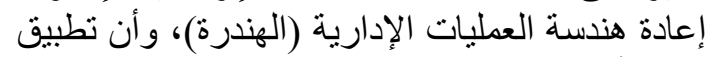

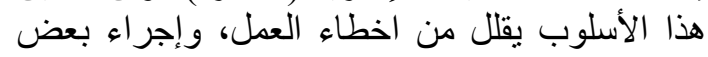

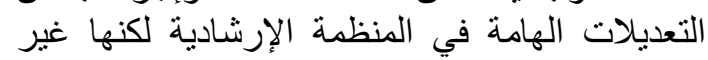
جذرية، ومساهمة تطبيق اسلوب الزئنة الهندرة في سهولة الزئة

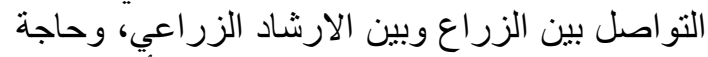

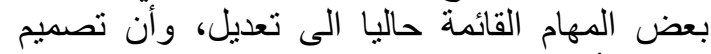

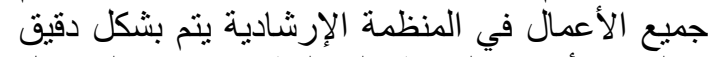

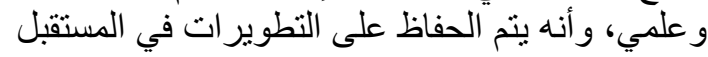

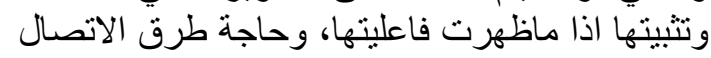

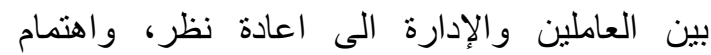

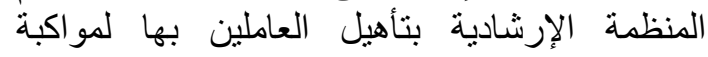
متطلبات المهام الجديدة، وتفعيل استخدام تكنولوجيا لميل 
الامكانات المادية اللازمة، وتطبيق نظم الهندرة بصورة تدريجية حتى لا يحدث خلل في الهيكل الارشادي، ولادئ وتحسين

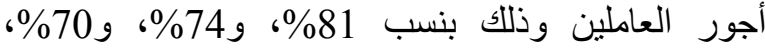

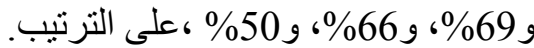

ثالثا: معوقات تطبيق اسلوب إعادة العادة هندسة العمليات

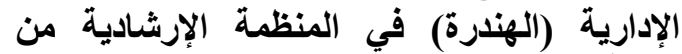
وجهة نظر المبحوثين.

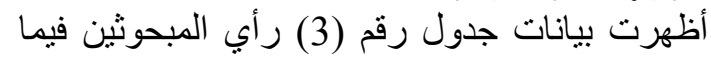

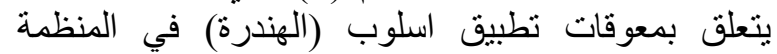

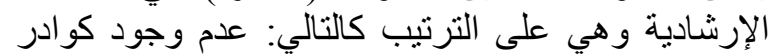

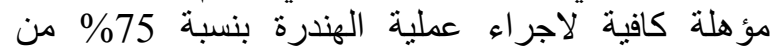

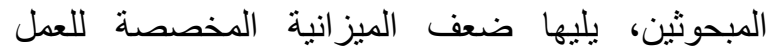

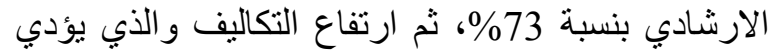

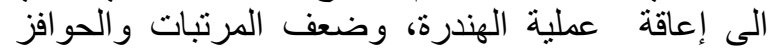
المادية وذللك بنسبة 70\% لكلا منهما، و عدم توافية وافر

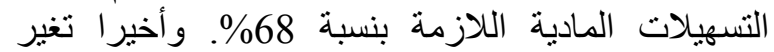
الظروف البيئية والمجتمعية المحيطة بالجهاز الارشادية

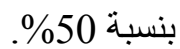

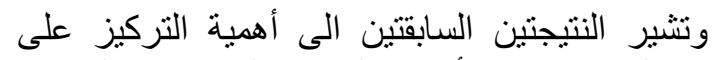

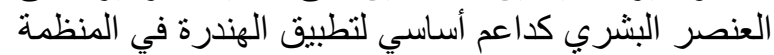

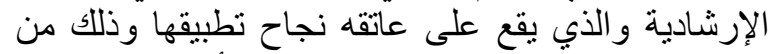

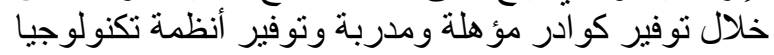

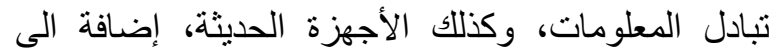

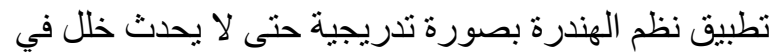

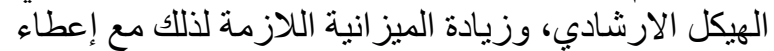

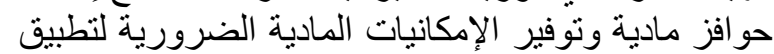

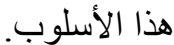
الأهمية التطبيقية للبحث ترجع أهمية هذا البحث البحثية الى كونه أحد البحوث التي تلقي

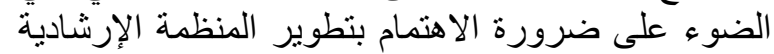

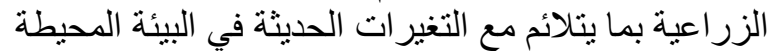

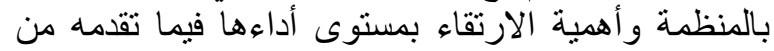

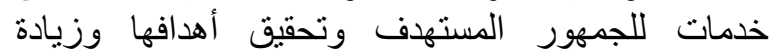
فعاليتها في مو اكبة لتغيير ات في البيئة المحيطة وما بهات الها من وند

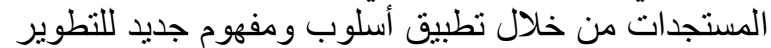
و هو الهندرة - وهو من المفاهيم الحديثة في حقل الإدارة،

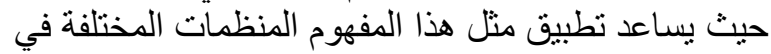

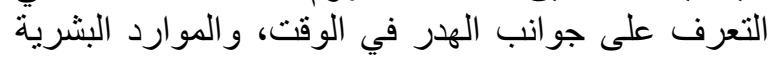

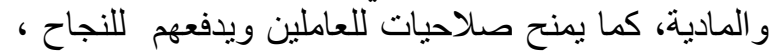

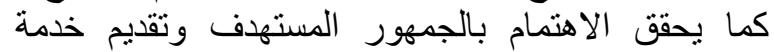

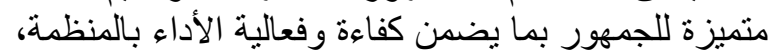

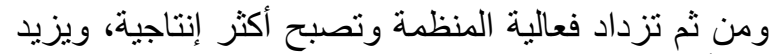

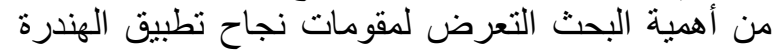

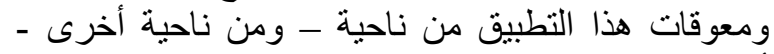

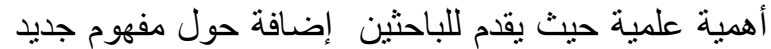
هو أعادة الهندسة.
وقد جمعت بيانات البحث خلال الفترة من مارس الى ولى ابريل عام 2019 ، وتم استخدام التكرار و النسبة المئوية

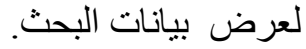

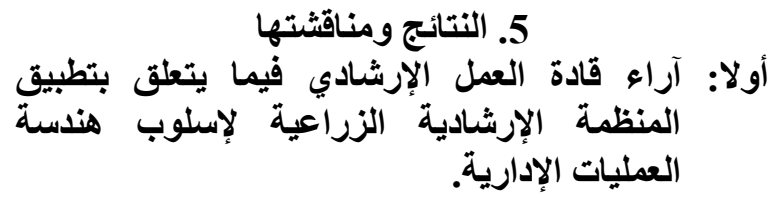

أـ تبسيط إجراءات العمل : أوضحت النتائج، كما هو مبين النين

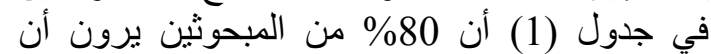
تطبيق أسلوب إعادة هندسة العمليات الإدارية

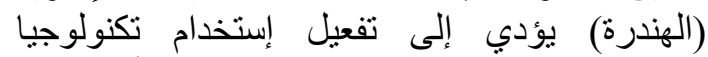

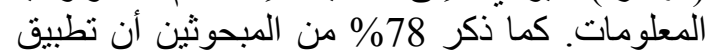

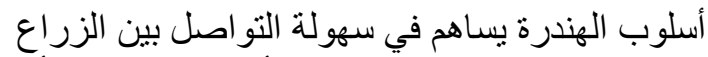

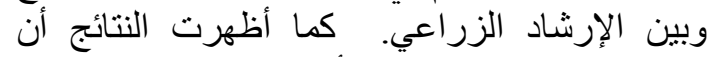

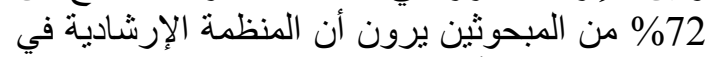

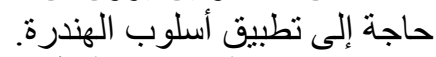

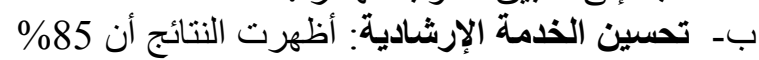

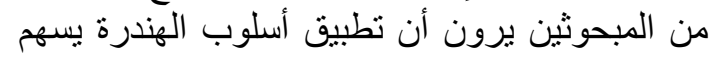

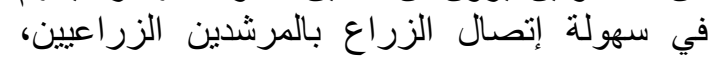

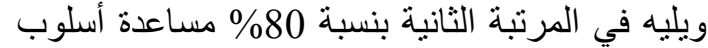
الهندرة في تقديم خدمة إرشادية جيدة لتحنة لتحقيق رضا

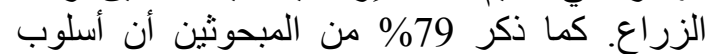

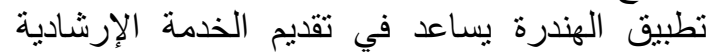
للزراع في الوقت المناسب. كما يساعد في سرعة الإرة

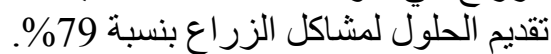

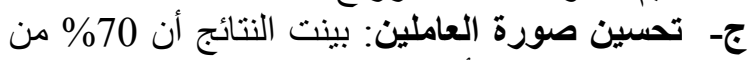

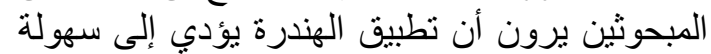

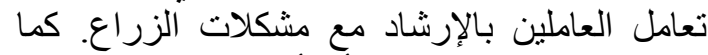

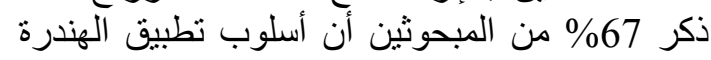

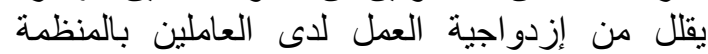
الإرشادية. كما ذكر 50\% من إلبة المبحوثين أن نطبيقه يؤدي إلى زيادة إنتاجية العمل.

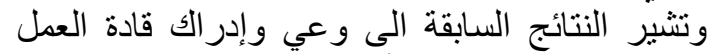

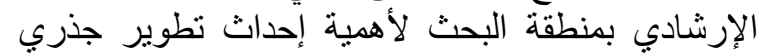

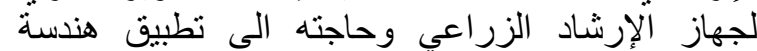
العمليات الإدارية خاصة في ظل التئة التطور الهائل في البيئة

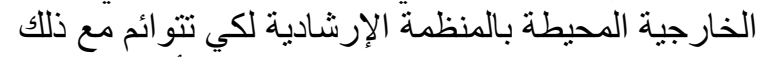

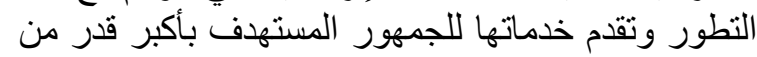

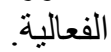

ثانيا: عوامل نجاح تطبيق اسلوب (الهندرة) في المنظمة الإرشادية من وجهة نظر المبحوثين.

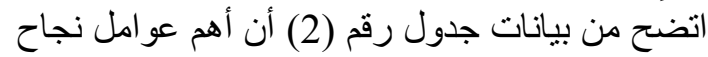
تطبيق اسلوب إعادة هندسة العمليات الإدارية (الهندرة) في الإنية

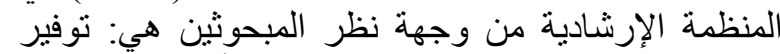

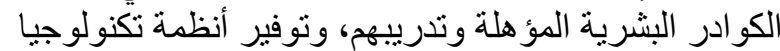

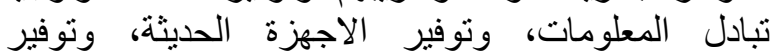




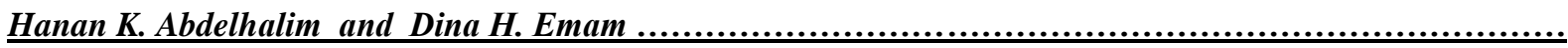

جدول (1): آراء قادة العمل الإرشادي فيما يتعلق بتطبيق المنظمة الإرشادية الزراعية لإسلوب هندسة العمليات الإدارية.

\begin{tabular}{|c|c|c|c|c|c|c|c|c|c|}
\hline \multicolumn{8}{|c|}{ \% النسبة المئوية لاستجابات المبحوثين } & \multirow{3}{*}{ 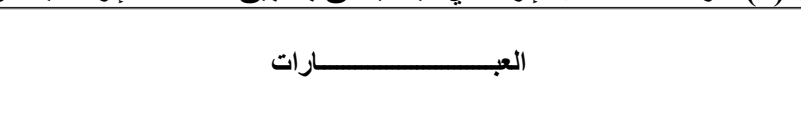 } & \multirow[t]{3}{*}{ ? } \\
\hline \multicolumn{2}{|c|}{ لا لآوافق } & \multicolumn{2}{|c|}{ أوافق بلرجة قليلة } & \multicolumn{2}{|c|}{ اوافق بلرجة متوسطة } & \multicolumn{2}{|c|}{ اوافق بلرجة كبيرة } & & \\
\hline$\%$ & $ت$ & $\%$ & $ت$ & $\%$ & $ت$ & $\%$ & $ت$ & & \\
\hline & & 1 & 1 & 27 & 38 & 72 & 101 & 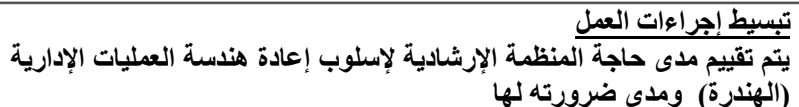 & 1 \\
\hline & & 4 & 6 & 28 & 39 & 68 & 95 & تطبيق اسلوب إعادة هندسة العمليات الإدارية يقلل من اخطاء العمل. & 2 \\
\hline 8 & 11 & 14 & 20 & 51 & 71 & 27 & 38 & تمتعداداء للبدء في التعندرة الهامة في المنظمة الإرشادية لكنها غير جذرية وذلك & 3 \\
\hline & & 2 & 3 & 20 & 28 & 78 & 109 & التواصل بين الزراع وبين الارشلوباد الزراعي. العمليات الإدارية (الهندرة) الى سهولة & 4 \\
\hline 2 & 3 & 3 & 4 & 35 & 49 & 60 & 84 & تحتاج بعض المهام القائمة حاليا الى تعديل & 5 \\
\hline 9 & 13 & 17 & 24 & 32 & 45 & 42 & 59 & تم تصميم جميع الأعمال في المنظمة الإرشادية بشكل دقيق وعلميي & 6 \\
\hline & & 1 & 1 & 30 & 42 & 69 & 97 & يتم الحفاظ على التطويرات في المستقبل وتثبيتها اذا ماظهرت فاعليتها & 7 \\
\hline 2 & 3 & 3 & 4 & 51 & 71 & 44 & 62 & تحتاج طرق الاتصال بين العاملين والإدارة الى اعادة نظر & 8 \\
\hline & & 22 & 50 & 22 & 50 & 56 & 78 & تهتم المنظمة الإرشادية بتأهيل العاملين بها لمواكبة متطلبات المهام الجديدة & 9 \\
\hline 4 & 6 & 4 & 6 & 12 & 17 & 80 & 112 & استخذام تكنوليق اسلوبي المعلومات إعادة هندة العمليات الإدارية (الهندرة) الى تفعيل & 10 \\
\hline 23 & 32 & 21 & 29 & 44 & 62 & 12 & 17 & تعتبر طريقة تقسيم العمل بالمنظمة الإرشادية غير فعالة & 11 \\
\hline 1 & 1 & 1 & 1 & 19 & 27 & 79 & 111 & 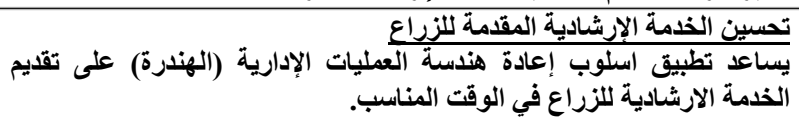 & 12 \\
\hline 1 & 1 & - & & 14 & 20 & 85 & 119 & تصبيق الزراع بالمرشدين هندادة العيلين العمليات الإدارية (الهندرة) يسهم في سهولة & 13 \\
\hline 8 & 11 & 2 & 3 & 17 & 24 & 73 & 102 & الخدمة الارشيادية للزبلواع اعادة هندة العمليات الإدارية (الهندرة) على تحسين & 14 \\
\hline 25 & 35 & 20 & 28 & 24 & 34 & 31 & 43 & زيارات الزراع للجمعية الزراعية أو المركز الإرشيادية (الهندرة) يساعد على تقليل & 15 \\
\hline 1 & 1 & 4 & 6 & 16 & 22 & 79 & 111 & الحلولم لمشاكل الزراع. إعادة هندة العمليات الإدارية (الهندرة) في سرعة تقليم & 16 \\
\hline- & & 6 & 8 & 14 & 20 & 80 & 112 & تطبيق اسلوب بإعادة هندسة العليقات الإدادارية (الهندرة) يساعد في تقايم خدمة & 17 \\
\hline 3 & 4 & 13 & 18 & 26 & 36 & 58 & 81 & لتقلّل تطبيق اسلوب الإرشادية للزراعة هندة العمليات الإدارية (الهندرة) من الوقت الازم & 18 \\
\hline- & & 2 & 3 & 35 & 49 & 63 & 88 & 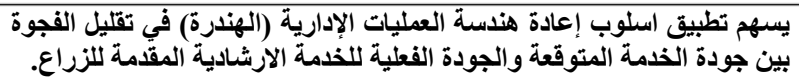 & 19 \\
\hline 20 & 28 & 5 & 7 & 34 & 48 & 41 & 57 & تعلية الهندرة ستزيل من ملنين ولاء العاملين & 20 \\
\hline 60 & 84 & 3 & 4 & 12 & 17 & 25 & 35 & قبل القيام بالتظوير لا يتم القيام بتثخيص الوضع الراهن & 21 \\
\hline 47 & 66 & 18 & 25 & 19 & 27 & 16 & 22 & تؤدي عملية الهندرة الى انخفاض في معنويات العاملين & 22 \\
\hline 55 & 77 & 13 & 18 & 18 & 25 & 14 & 20 & لا حاجة لمراجعة المهام وتوصيفها باستمرار & 23 \\
\hline 18 & 25 & 9 & 13 & 36 & 50 & 37 & 52 & تفتقر منظمتنا الى تدعيم التطويرات بعد إحداثها والى تحديثها باستمرار & 24 \\
\hline 31 & 43 & 12 & 17 & 16 & 22 & 41 & 57 & 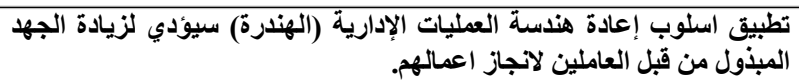 & 25 \\
\hline 60 & 84 & 16 & 22 & 20 & 28 & 4 & 6 & 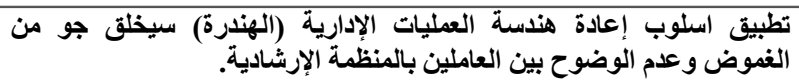 & 26 \\
\hline 58 & 81 & 20 & 28 & 10 & 14 & 12 & 17 & لا يتم تدريب العاملين على التغييرات التي تحدثها المنظمة الإرشادية & 27 \\
\hline 51 & 71 & 23 & 32 & 14 & 20 & 12 & 17 & لا يعتبر التغيير حافزا لي لزيادة اتقان العمل & 28 \\
\hline 7 & 10 & 10 & 14 & 33 & 26 & 50 & 70 & ادت التغييرات الجديدة الى زيادة إنتاجية العمل & 29 \\
\hline 22 & 31 & 6 & 9 & 45 & 63 & 27 & 38 & ادت التغييرات الجديدة الى زيادة ولاء واندفاع العاملين & 30 \\
\hline 44 & 62 & 10 & 14 & 31 & 43 & 15 & 71 & يؤدي التغيير الى ترك العاملين لعملهم مهما كان موقعهم الوظيفي & 31 \\
\hline 6 & 9 & 6 & 9 & 43 & 60 & 45 & 63 & تلطبيق اسلوب إعادة هندامة العمل العمليات الإدارية (الهندرة) يشجع العاملين على & 32 \\
\hline 3 & 4 & 5 & 7 & 22 & 31 & 70 & 98 & تعاؤدل العامليق بالإرشاد مع مشكلات الزراعة العمليات الإدارية (الهندرة) الى سهولة & 33 \\
\hline 2 & 3 & 6 & 9 & 25 & 35 & 67 & 94 & العطيق للى العلوبلين بالمنظمة الإرشادية العليات الإدارية (الهندرة) يقلل من من ازدواجية & 34 \\
\hline 9 & 13 & 19 & 27 & 24 & 34 & 48 & 67 & يؤدي التّريب على رأس العمل لزيادة الولاء لاى الأفراد. & 35 \\
\hline
\end{tabular}




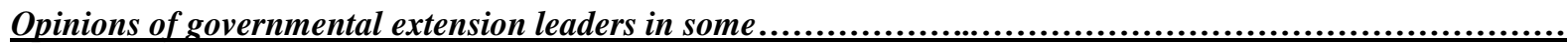

جدول (2): عو امل نجاح تطبيق اسلوب إعادة هندسة العمليات الإدارية (الهندرة) في المنظمة الإرشادية.

\begin{tabular}{|c|c|c|c|}
\hline$\%$ & $ت$ & 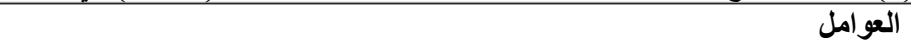 & \\
\hline 81 & 113 & توفير الكوادر البشرية المؤهلة وتدريبهم & 1 \\
\hline 74 & 104 & توفير أنظمة تكنولوجيا تبادل المعلومات & 2 \\
\hline 70 & 98 & توفير الاجهزة الحديثة & 3 \\
\hline 69 & 97 & توفير الامكانات المادية اللازمة & 4 \\
\hline 66 & 92 & تطبيق نظم الهندرة بصورة تدريجية حتى لا يحدث خلل في الهيكل الارشادي & 5 \\
\hline 50 & 70 & تحسين أجور العاملين & 6 \\
\hline 42 & 59 & التقيم الدوري وكتابة تقارير بذلك لتحديد نقاط القوة والضعف & 7 \\
\hline 20 & 28 & التسيق بين المنظمات الزراعية وغير الزراعية العاملة في الريف & 8 \\
\hline 23 & 32 & تحرير العمل الارشادي من قيود الروتين الحكومي & 9 \\
\hline 34 & 48 & تقوية العلاقة بين البحث الزراعي والتعليم الفني الزراعي وجهاز الارشاد الزراعي & 10 \\
\hline 17 & 24 & مشاركة المرشدين في تخطيط وتنفيذ وتقويم البرامج الارشاديةة & 11 \\
\hline 4 & 6 & الاستفادة من خبرات القادة الارشاديين المحليين & 12 \\
\hline
\end{tabular}

جدول (3): معوقات تطبيق اسلوب إعادة هنسة العمليات الإدارية (الهندرة) في المنظمة الإرشادية من وجهة نظر المبحوثين.

\begin{tabular}{|c|c|c|c|}
\hline$\%$ & ت & المعوقات & \\
\hline 75 & 105 & عدم وجود كوادر مؤهلة كافية لاجراء عملية الهندرة & 1 \\
\hline 73 & 102 & ضعف الميزانية النخصصة للعمل الارشادي & 2 \\
\hline 70 & 98 & ارتفاع التكاليف يمكن اعاقة عملية الهندرة & 3 \\
\hline 70 & 98 & ضعف المرتبات والحوافز المادية & 4 \\
\hline 68 & 95 & عدم توافر التسهيلات المادية اللازمة & 5 \\
\hline 50 & 70 & تغير الظروف البيئية والمجتمعية المحيطة بالجهاز الارشادي & 6 \\
\hline 40 & 56 & ندرة قو اعد البيانات والمعلومات الخاصة بتحديث الزراعة في مصر . ـ. & 7 \\
\hline 33 & 26 & صعوبة توفر الدعم الفني والاشر اف الارشادي للمرشدين على مستوى القرية & 8 \\
\hline 20 & 28 & علدم وجود سياسة واضحة ومتكاملة للإرشاد الزراعي على المستوى الوطني & 9 \\
\hline
\end{tabular}

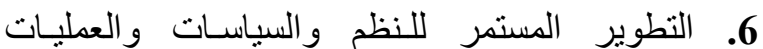

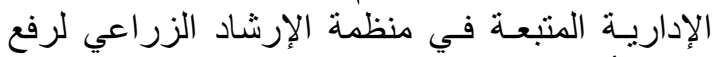
وزيادة أداء العاملين.

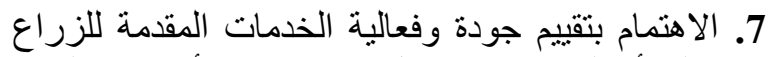
و المر أة الريفية من خلال حجم وعدد النشطة والئمة المهام التي يتم انجاز ها.

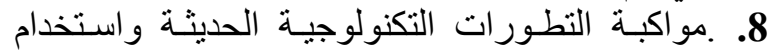
البر امج المتطورة الداعمة لتنفيذ الأساليب الحديثة في العي

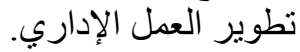
9. نمية الموارد البشرية بالإرشاد الزراعي من خلادل

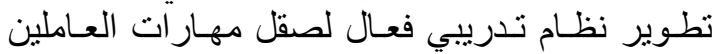

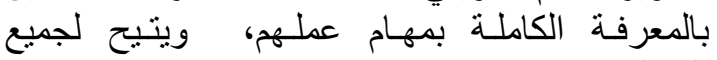

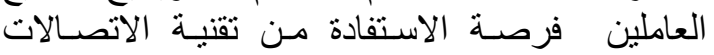

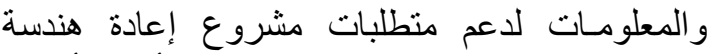
العمليات الإدارية "الهندرة" ليتمكنو المن أداء الأعمال بكفاءة.

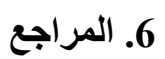

الأغا، مرام إسماعيل (2006). دراسة تطبيقية لإعادة العادية هندسة العمليات الإدارية "الهندرة" في المصارف
1. أنتصيات بت اعداد الهيكل التنظيمي باستخدام الهندرة كأحد

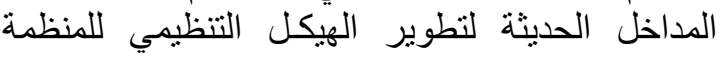

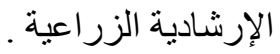

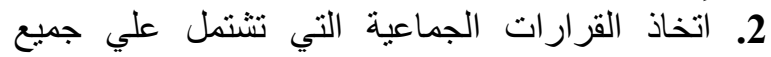

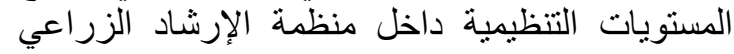

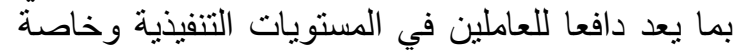
المرشدين الزراعيين للاهتمام بتنفيذ هذه القرارين

ودعمها 3. أن يتم التركيز على تسلسل أنشطة العمل عند اعداد

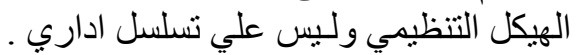

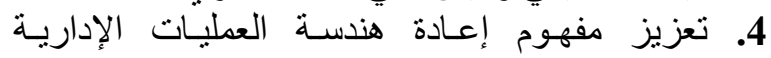

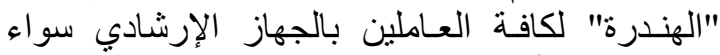

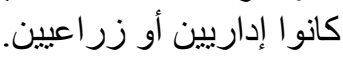

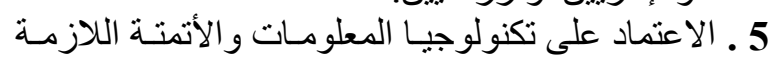
للدعم تطبيق منهج إعادة هندسة العمليات الإدارية الإنية

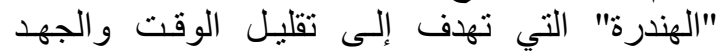

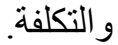




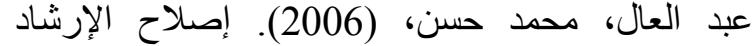

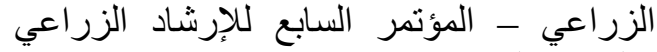

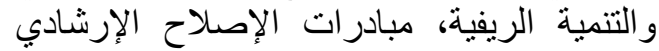

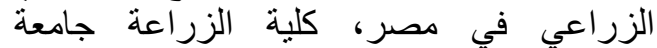

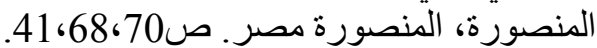

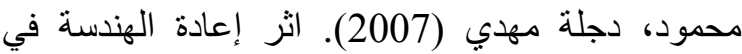

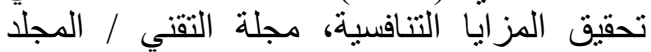

العشرون/ العدد ب، هيئة التعليم التقني، وزارة التئية

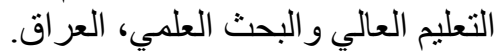

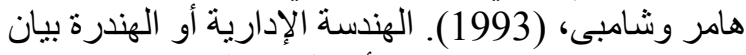

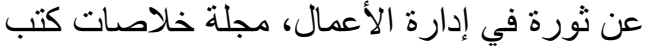
المدير ورجال الاعمال، العدد 20، أكتوبر.

Hammer M. and Champy J.(1995). Information Technology for Management Reengineerings the Corporation: A Manifesta for Business Révolution, (New York, NY: Harper Business) p.19.

Jerva M. (2001). BPR and Systems Analysis and Design Making: The Case for Integration, Topics in Health Information Management, Vol 3 (4):15-20.

Kora G. and Kassem M. (2010). The Application of Information and Communication Technologies in Agricultural and Rural Development in Egypt, FAO, Rome,Italy. Available at: http://fao.org/docrep/013/i1930/e00.pdf

Neill P. and Sohal A. (1999). "Business process reengineering: a review of recent literature", Technovation.19, No. 9 p.574.

Paul A. and Cespedes S. (1995). "Reengineering is Just A Catalyst in Bank Culture Change", The Bankers Magazine, MayJune, 3 (1):36

Qamar M. K. (2005). Modernizing National Agricultural Extension System, A Practical Guide for Policy Makers of Developing Countries, F.A.O. Rome, Italy. :vii

Raymond I. and Bergeron F. (1998). "Determinants of Business Process Reengineering Success in Small and Large Enterprises: An empirical study in canadian context". J. Small Bus. Manag., 36. 1, p.72.

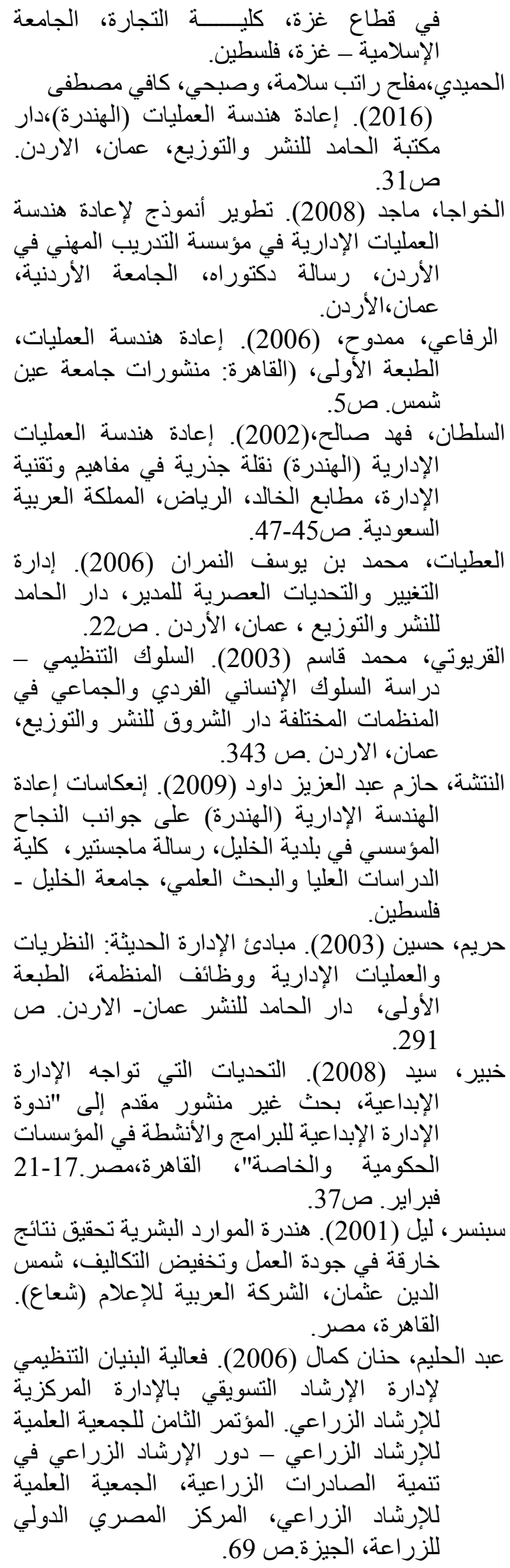

